\title{
Análise do processo de trabalho no núcleo de apoio à saúde da família em município do nordeste brasileiro*
}

\section{Working Process Analysis in Support Center to Family Health in Brazilian Northeast County}

\section{Análisis del proceso de trabajo en centro de apoyo a la salud de la familia ciudad del noreste de Brasil}

Fecha de recepción: 27-07-15 Fecha de aceptación: 28-04-16 Disponible en línea: 03-05-16 doi:10.11144/Javeriana.rgyps15-30.aptn

Cómo citar este artículo:

Vieira de Macedo MA, Ximenes-Guimarães JM, Coelho-Sampaio JJ, Pereira-Morais AP, Carneiro C.

Análise do processo de trabalho no núcleo de apoio à saúde da família em município do nordeste brasileiro. Rev. Gerenc. Polít. Salud. 2016; 15(30): 194-211. http://dx.doi.org/10.11144/Javeriana.rgyps15-30.aptn

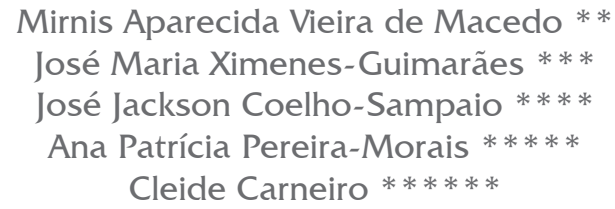

** Fisioterapeuta. Especialista em Saúde da Família. Egressa do Curso de Especialização em Saúde da Família da Universidade Estadual do Ceará. E-mail: mirnisv@hotmail.com

*** Enfermeiro Sanitarista. Doutor em Saúde Coletiva. Professor Substituto da Universidade Estadual do Ceará. Endereço: Rua Júlio Cesar, 1830, Apto 201; Bairro Damas, Fortaleza, Ceará, Brasil. CEP 60.435-808. E-mail: jose. ximenes@uece.br

***** Médico. Doutor em Medicina Preventiva. Professor Titular de Saúde Pública da Universidade Estadual do Ceara E-mail: jose.sampaio@uece.br

****** Enfermeira. Doutora em Saúde Pública. Professora Adjunta da Universidade Estadual do Ceará. E-mail: anapatricia.

194 morais@uece.br cleide.carneiro@uece.br 


\section{Resumo}

Objetivo: analisar a organização do processo de trabalho do Núcleo de Apoio à Saúde da Família (NASF). Método: pesquisa qualitativa, com 11 pro ssionais de duas equipes de nasf em Fortaleza, Ceará. A coleta de dados foi por meio de entrevista semiestruturada e observação livre, com análise baseada na Hermenêutica-Dialética. Resultados: evidenciaram-se descompassos da formação em relação à proposta de trabalho do nasf, precárias condições laborais e di culdades de articulação e pactuações de apoio à Estratégia Saúde da Família-esf, bem como potencialidades como trabalho em equipe, à cogestão e compartilhamento das ações. O NASF foi reconhecido como apoio à ESF, entretanto, ainda não consegue atuar de modo a efetivar as diretrizes propostas pelo Ministério da Saúde. Conclusão: há necessidade de discussão crítica e repactuação dos processos de trabalho no nasf, com vistas a materializar suas diretrizes, orientadas pelo atendimento às necessidades de saúde da população.

Palavras-chave: atenção primária à saúde; estratégia saúde da família; conhecimentos, atitudes e prática em saúde; políticas, planejamento e administração em saúde; gestão em saúde; pesquisa qualitativa

\section{Abstract}

Objective: To analyze the organization process of Family Health Care Centers (NASF's). Method: qualitative research, with two teams of 11 Family Health Care Centers (NASF's) professionals in Fortaleza, Ceará. The data were collected through semi-structured interview and free observation, with analysis based on Hermeneutics-Dialectic. Results: divergences occurred in relation to the proposed work of the (NASF's), precarious working conditions and dif culties of articulation and settlements to support Family Health Strategy (ESF), as well as potential as teamwork, the co-management and shared actions. The Family Health Care Centers (NASF's) was recognized as a support to the Family Health Strategy (ESF), however, it can't work yet in an effective way to the proposed guidelines by the Health Ministry. Conclusion: It's necessary a critic discussion and a new agreement of the Family Health Care Centers (NASF's) working process, in order to materialize its guidelines, directed by attendance to the necessities of the population.

Keywords: Primary Health Care; Family Health Strategy; Health Knowledge, Attitudes, Practice; Health Policy, Planning and Management; Health Management; Qualitative Research.

\section{Resumen}

Objetivo: analizar la organización del proceso de trabajo del Núcleo de Apoyo para la Salud de la Familia (NASF). Método: estudio cualitativo, con once profesionales de nasf en Fortaleza, Ceará, Brasil. Los datos fueron obtenidos mediante entrevistas semiestructuradas y observación libre. El análisis se basó en la hermenéutica-dialéctica. Resultados: inadecuada formación en relación con la función de los nasf, precarias condiciones laborales y di cultades para coordinar el apoyo entre el NASF y la ESF; las potencialidades fueron el trabajo en equipo, la cogestión y el compartir actividades. El NASF es un instrumento de apoyo a la ESF, pero aún no actúa de modo efectivo, de acuerdo con el Ministerio de Salud. Conclusión: se necesita exigir un debate crítico y la renegociación de los procesos de trabajo en NASF, con el $\mathrm{n}$ de hacer que se materialicen sus directrices, orientadas a satisfacer las necesidades de salud de la población.

Palabras clave: atención primaria de salud; estrategia de salud familiar; conocimientos, actitudes y práctica en salud; políticas, plani cación y administración en salud; gestión en salud; investigación cualitativa 


\section{Introdução}

No contexto de implantação do Sistema Único de Saúde (sus), dentre as iniciativas direcionadas à mudança do modelo de atenção, encontra-se a Estratégia Saúde da Família (ESF), instituída como programa governamental pelo Ministério da Saúde em 1994. Configura-se como proposta que possibilita a materialização dos princípios e diretrizes do sistema de saúde brasileiro, impulsionando a reorganização da atenção básica, aqui denominada Atenção Primária à Saúde (APS), por induzir o desenvolvimento de novos modos de organizar serviços e práticas de saúde. Contribui, portanto, para que a universalidade do acesso aos serviços de saúde, integralidade do cuidado, equidade e participação social sejam operacionalizadas no cotidiano do sus.

O crescimento acelerado e os avanços alcançados pela ESF permitem sua consolidação como modelo de atenção reorientador da APS, mediante a ampliação de sua resolubilidade e operacionalização de seus atributos. Assim, constitui-se ordenadora das redes de atenção à saúde e coordenadora do cuidado, potencializando a horizontalidade e a longitudinalidade do cuidado ante as complexas demandas expressas na atenção voltada para a família no seu território social $(1,2)$.

Na perspectiva de apoiar o trabalho das equipes da ESF, ampliando a oferta de cuidado e a resolubilidade da APS, foram criados em 2008, pelo Ministério da Saúde, os núcleos de apoio à Saúde da Família (NASF), vinculados a um número variável de equipes da ESF, de três a 15, podendo ser compostos por profissionais de diversas áreas, entre elas: Fisioterapia, Terapia Ocupacional, Fonoaudiologia, Nutrição, Psicologia, Serviço Social, Farmácia, Educação Física e algumas especialidades médicas. A delimitação dos componentes da equipe de NASF deve consi- derar como critérios as prioridades identificadas com base no perfil epidemiológico, nas necessidades de saúde locais e das equipes de saúde a serem apoiadas (3).

Convém assinalar que as ações do NASF devem ser desenvolvidas em articulação com as das equipes da ESF, orientadas pela integralidade do cuidado, aqui compreendida em três dimensões: a) apoio às práticas em saúde nos territórios adscritos da equipe da ESF, com garantia de cuidado longitudinal, considerando as necessidades de saúde de sujeitos e coletivos, com vistas a superar a fragmentação dos processos de cuidar; b) organização das práticas de saúde integrando ações de promoção, prevenção e reabilitação da saúde e cura, além de humanização dos serviços e educação permanente; e c) a organização do sistema de saúde, garantindo acesso às redes de atenção conforme as necessidades da população $(3,4)$.

A atuação do NASF deverá privilegiar ações no âmbito das seguintes áreas estratégicas: Atividade Física e Práticas Corporais; Práticas Integrativas e Complementares; Reabilitação/Saúde Integral da Pessoa Idosa; Alimentação e Nutrição; Saúde Mental; Serviço Social; Saúde da Criança e do Adolescente e do Jovem; Saúde da Mulher e Assistência Farmacêutica. A prioridade recai, porém, sobre os atendimentos em grupo e compartilhados com a ESF, na perspectiva de conferir maior qualidade à atenção à saúde, não se restringindo apenas à ampliação quantitativa da oferta de ações na APs. Para tanto, não constitui porta de entrada do sistema, mas apoio às equipes da ESF as quais se vincula $(5,6)$.

Entende-se que compete ao NASF oferecer suporte à ESF na sua articulação e inserção nas diversas redes de atenção à saúde e serviços que as integram, incluindo-se ainda as redes sociais e comunitárias do território, 
trabalhando em uma perspectiva intersetorial, garantindo o cuidado longitudinal, integral e resolutivo, conforme as necessidades da população.

Com efeito, a atuação do NASF contrapõe-se ao modelo de atenção convencional — centrado na assistência curativa, individual e fragmentada - ao propor uma lógica de trabalho que avança em direção à corresponsabilização e cogestão do cuidado, mediante a execução de atendimentos compartilhados com a ESF, considerando as singularidades dos sujeitos.

Ao se abordar a atuação dos profissionais do NASF, considerando a nova lógica de trabalho que deve orientar a sua prática, adota-se a perspectiva teórica do processo de trabalho em saúde, entendido como uma atividade de produção dinâmica e relacional, que incorpora distintas tecnologias - condutas terapêuticas, instrumentos e ferramentas-e se realiza, fundamentalmente, pela intervenção criativa do trabalhador, constituindo, portanto, um trabalho vivo em ato. Assinala-se, ainda, a ideia de que o produto se expressa em processos produtivos de atos cuidadores consumidos no momento de execução (7). Destaca-se que o modo de organização do processo de trabalho, particularmente no âmbito da APS, constitui um dos eixos centrais na reorientação da atenção à saúde no sus.

Para tanto, a organização do processo de trabalho do NASF deve incorporar tecnologias que permitam a gestão e produção do cuidado integral, potencializando a materialização de suas diretrizes operacionais, entre estas a Clínica Ampliada, o Projeto Terapêutico Singular (PTS), o Projeto de Saúde no Território (PST), o Apoio Matricial e os Contratos de Pactuação de Apoio $(8,9)$. Torna-se necessário, portanto, o desenvolvimento de novos saberes e modos de intervenção construídos em equipe numa perspectiva interdiscipli- nar. Considerando-se que o apoio matricial constitui diretriz fundamental que orienta o processo de trabalho do NASF, possibilitando a ampliação da resolubilidade da ESF, destaca-se que este pretende ofertar tanto retaguarda assistencial quanto suporte técnico-pedagógico às equipes apoiadas; depende da personalização da relação entre equipes de saúde, da ampliação dos cenários em que se realiza a atenção à saúde e da elaboração compartilhada das diretrizes clínicas e sanitárias entre os componentes de uma equipe da ESF e os especialistas do NASF, que devem oferecer apoio matricial (9).

Com base na discussão aqui delineada, pressupõe-se que o NASF tem uma proposta inovadora, com potencialidade para mudança do modelo de atenção, mas que também são expressos desafios a serem superados com vistas à sua consolidação. De tal modo, se questiona: de que modo os trabalhadores do NASF organizam seu processo de trabalho, considerando que a reorientação modelo de atenção se articula à implementação de suas diretrizes operacionais? Quais estratégias de gestão e de produção do cuidado integral são operadas no cotidiano das equipes?

Com efeito, este estudo teve como objetivo analisar a organização do processo de trabalho das equipes do NASF, considerando as suas potencialidades e desafios na gestão e produção do cuidado em articulação com a Estratégia Saúde da Família.

\section{Percurso metodológico}

Trata-se de pesquisa exploratória, com abordagem qualitativa, numa perspectiva critico-reflexiva. Elegeu-se como objeto de análise a práxis de um grupo social, mais particularmente, a organização do processo de trabalho de equipes dos núcleos de apoio à Estratégia Saúde da Família, configurando-se 
como um campo permeado por intensa produção subjetiva, a qual também determina a produção de sentidos e significados atribuídos aos fenômenos sociais, resultantes da trama intersubjetiva tecida no contexto das relações estabelecidas entre os diferentes sujeitos que integram esta realidade. Nestes termos, a abordagem qualitativa de investigação em saúde, mostra-se adequada por se considerar que a singularidade desta experiência em suas múltiplas dimensões não é passível de ser reduzida à mensuração quantitativa.

A pesquisa ocorreu em município de grande porte da Região Nordeste do Brasil, que em sua organização político-administrativa descentraliza a implementação e execução das políticas e ações governamentais para unidades administrativas, denominadas Secretarias Executivas Regionais (SER), responsáveis por um território delimitado, totalizando sete SER, no período de execução do estudo. A implantação do NASF no Município se deu em 2009, tendo 28 equipes em funcionamento no período de realizado do estudo, todas na modalidade I, sob gestão municipal. O campo empírico foi demarcado intencionalmente, sendo eleito o território da SER IV, onde atuam três equipes, adotando-se como critério a viabilidade de execução do estudo, por se tratar de serviços que configuram campo de ensino e extensão da Universidade Estadual do Ceará, por meio de parceria entre esta instituição de ensino e a Secretaria Municipal de Saúde. Por conseguinte, os autores têm fácil inserção nas unidades de saúde. Destaca-se o fato de que somente duas equipes integraram a investigação, pois a terceira estava incompleta no momento do estudo.

No concernente à delimitação da amostra qualitativa do estudo, consoante as premissas que norteiam a pesquisa qualitativa, não se conferiu relevância ao critério da representatividade estatística, mas ao acú- mulo subjetivo dos sujeitos ante o objeto em apreensão, resultante da sua implicação com o mesmo. Os 11 trabalhadores das equipes de NASF selecionadas, contudo, foram eleitos sujeitos da pesquisa, por se constituírem informantes-chave ante a experiência que acumulam, pois são responsáveis pela organização de seu processo de trabalho. Estes representam oito categorias profissionais, sendo um psicólogo, dois fisioterapeutas, dois assistentes sociais, um nutricionista, dois fonoaudiólogos, um terapeuta ocupacional, um farmacêutico e uma biomédica. Convém assinalar que, no município onde se realizou o estudo, as equipes de NASF não contam na sua composição com profissionais médicos.

Os participantes do estudo são predominantemente do sexo feminino, sendo apenas um do sexo masculino. No referente à idade, estão na faixa de 25 a 55 anos; com tempo de graduado variando de 1,5 a 17 anos; sete profissionais atuam no NASF há dois anos; em relação à formação, oito possuem especialização áreas do conhecimento diversas, uma com mestrado. Dois profissionais, de menos tempo de formado, contudo, são apenas graduados.

Os dados foram obtidos por meio de entrevista semiestruturada, orientada pelo roteiro com perguntas abertas, privilegiando questões sobre a organização e as condições de trabalho, as ações desenvolvidas e a articulação com as equipes da Estratégia Saúde da Família. As entrevistas foram realizadas individualmente no ambiente de trabalho, em local reservado, mediante agendamento prévio e disponibilidade do participante. Estas foram gravadas, após a anuência do informante, com duração média de aproximadamente 35 minutos. Utilizou-se ainda a observação do campo empírico, particularmente as condições de trabalho e o processo de trabalho, registrando-se, em diário de campo, aspectos inerentes ao fenômeno sob investigação. 
O material empírico resultante da coleta de dados foi processado e analisado com base na Hermenêutica-Dialética, conforme proposto por Minayo (10). Considera-se que, do ponto de vista metodológico, a abordagem hermenêutica busca a compreensão dos fenômenos mediada pela linguagem. Assim, objetiva esclarecer o contexto dos diferentes sujeitos e das propostas que produzem, afirmando haver um teor de racionalidade e de responsabilidade. A dialética, por sua vez, possibilita a crítica e a apreensão das contradições na linguagem, valorizando os processos dinâmicos das contradições no interior das práticas sociais. A junção das duas abordagens conduz o intérprete ao entendimento do texto e do contexto, da fala e do depoimento, como resultantes de um processo social, com múltiplas determinações, porém com significado especifico $(10,11)$. Os passos operacionais do processo de análise dos dados são demonstrados no fluxograma, estruturado na figura 1 (12).

Destaca-se o fato de que, no processo de análise, as entrevistas constituíram o substrato principal para delimitação dos núcleos temáticos, sendo o conteúdo procedente das observações utilizado de forma complementar. $\mathrm{Na}$ análise, buscou-se identificar as convergências e divergências que permeiam o material discursivo, estabelecendo-se articulações com o referencial teórico orientador do estudo.

As normas que regulamentam a pesquisa envolvendo seres humanos foram respeitadas. Nesse sentido, todos os participantes manifestaram aquiescência em participar do estudo, mediante assinatura do Termo de Consentimento Livre e Esclarecido, no qual foram assegurados os seus direitos. A pesquisa foi aprovada pelo Comitê de Ética e

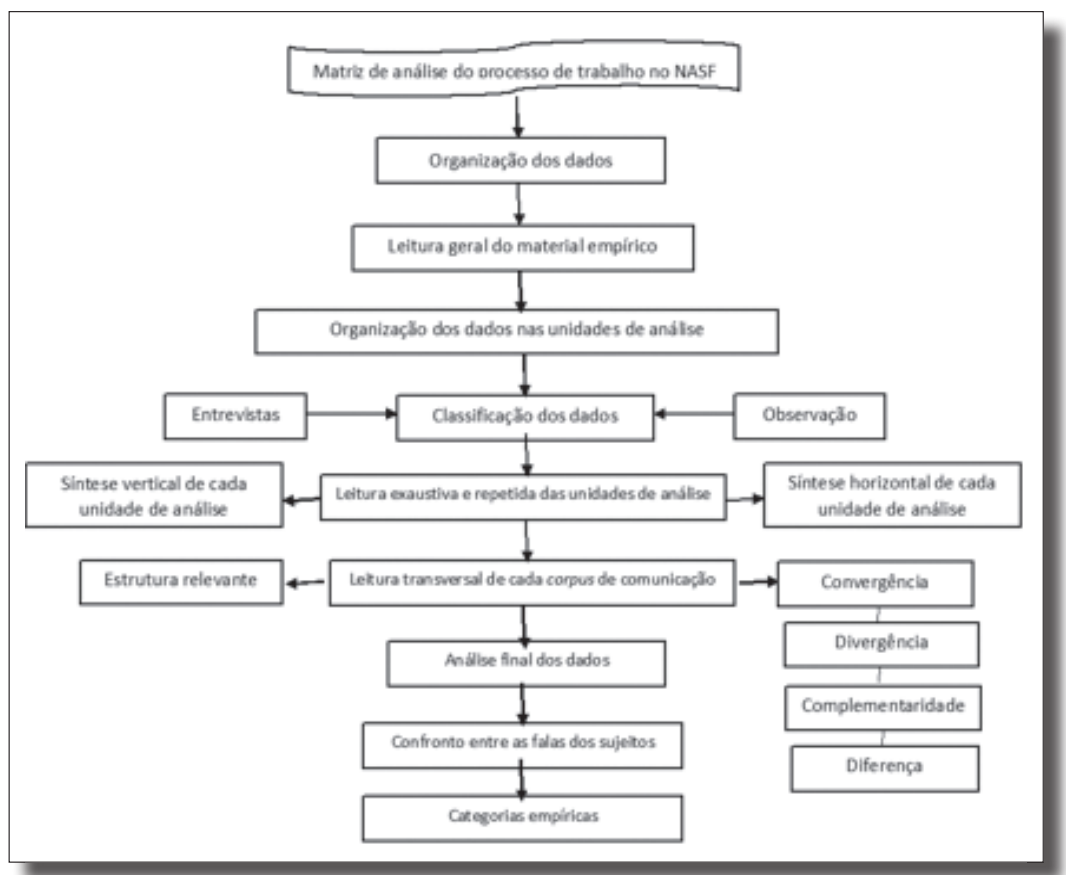

Figura 1. Fluxograma de desenvolvimiento da anÁlise hermenêtica-dialética

Fonte: Adaptado de Assis e Jorge (12) 
Pesquisa da Universidade Estadual do Ceará, com Processo no $11581625-9$.

\section{Resultados}

O processamento e a interpretação do material empírico permitiram a identificação dos eixos da análise empreendida e, consequentemente, a estruturação das categorias presentes nas informações acerca do processo de trabalho no NASF, as quais são apresentadas e discutidas a seguir.

\section{0 profissional e sua inserção na atenção primária à saúde: (des) encontros entre a formação e o mundo do trabalho}

No processo de construção do sus, a proposta de reorientação do modelo assistencial põe em relevo a necessidade de mudanças nos modos de atuação dos profissionais e de suas práticas, as quais são influenciadas pela formação recebida e o seu contexto político e histórico-social e sanitário. Aponta-se que, historicamente, os aspectos inerentes à gestão da força de trabalho no sus constituem um nó crítico. A consolidação do sistema de saúde, entretanto, mediante a materialização das mudanças propostas, requer o enfrentamento de problemas persistentes no que se refere à gestão do trabalho, dentre os quais a necessidade de formação e qualificação coerente com seus princípios e diretrizes, superação da precarização do trabalho e das condições de trabalho, existentes no sistema de saúde brasileiro, conforme assinala Guimarães (13) ao analisar os modelos de gestão no sus.

Nesse contexto, alguns profissionais do NASF afirmam que sua formação profissional não os qualificou para atuar na APs: primária e sim para atendimento clínico e hospitalar. [...] A formação era muito voltada para reabilitação, isso deixou uma marca na profissão, uma visão de profissionais reabilitadores, com uma visão focada nisso. Hoje, eu vejo a necessidade e realidade da promoção e prevenção na saúde e a sua importância. (NASF A, E4)

De modo convergente, as falas revelam a existência de lacuna no modelo de formação, por não instrumentalizar o profissional com o aporte de saberes, metodologias e técnicas de intervenção que lhes são requisitados no mundo do trabalho, particularmente quando se referem ao NASF e à implementação de práticas inovadoras, orientadas pela interdisciplinaridade e integralidade do cuidado. Evidencia-se a ideia de que a maioria dos profissionais atuantes nos NASF em estudo, independentemente de sua especialidade, compartilha da mesma proposta formadora, que se mostra dissonante em relação ao modelo de atenção que se propõe implantar no sus, no qual a ênfase está nas ações de promoção da saúde e prevenção, sem desconsiderar as ações de cura e reabilitação.

Ressalta-se o fato de que em ambas as equipes estudadas se encontraram profissionais com tempo de formado variando de um a 17 anos. O despreparo para atuar no âmbito da APS, desenvolvendo ações de promoção da saúde e prevenção, foi revelado pela maioria daqueles com maior tempo de conclusão do curso de graduação, dos quais a fala demonstrada acima é representativa. Pode-se inferir, portanto, que a formação destes profissionais foi orientada pelo modelo biomédico, centrado na atenção individual, curativa, tecnicista e fragmentada que se tenta superar.

Assim, a inserção destes profissionais no NASF se apresentou como dificuldade ou desafio, considerando a necessidade de deslocamentos da atuação na dimensão individual e reabilitadora para a atuação 
coletiva, numa perspectiva de articulação e compartilhamento das intervenções com a ESF. Deve-se acrescentar o entendimento de que este contexto requer dos profissionais competências para o trabalho em equipe numa abordagem interdisciplinar.

É de se reconhecer a realidade de que se acumula há anos a crítica ao modelo hegemônico de formação dos profissionais de saúde. Em distintas profissões da área, constituíram-se movimentos organizados em busca e produção de novos caminhos e estratégias para transformação e inovação nos cursos de graduação em saúde. Com a aprovação das diretrizes curriculares nacionais dos cursos de graduação em saúde, restou determinado que a formação do profissional de saúde deve privilegiar o sistema de saúde vigente no País, o trabalho em equipe e a atenção integral à saúde. Tal determinação legal inaugura outra lógica de formação em saúde, com vistas à superação do hiato entre o mundo da formação e o do trabalho (14).

Na realidade estudada, alguns profissionais, reconhecendo a lacuna existente na graduação no concernente aos conteúdos referentes à APS, buscaram participar de estratégias que pudessem complementar sua formação:

Infelizmente na minha época não tínhamos nenhuma disciplina voltada para atenção primaria, o máximo que consegui foi estágio extracurricular. (NASF B, E7)

Convém se reforçar o entendimento de que a atuação no sus requer uma formação profissional coerente com sua lógica institucional. Desse modo, faz-se necessária a efetiva reformulação dos currículos dos cursos de graduação na área da saúde. Observa-se o empreendimento de esforços nessa direção, sobretudo, com a implementação das Diretrizes Curriculares Nacionais (DCN), que determinam mudanças curriculares em todas as graduações em saúde, propugnando a integração ensino-serviço-comunidade como estratégia de formação articulada ao mundo do trabalho. Nesse sentido, desenvolvem-se projetos e/ou experiências que possibilitam a sua concretização, como Programa de Educação pelo Trabalho em Saúde (PET/ Saúde) (15).

Então, as mudanças ocorridas nos cursos de graduação já são reconhecidas pelos profissionais, particularmente aqueles com menor tempo de formados, conforme demonstra a fala a seguir:

Na minha formação tive disciplinas direcionadas à saúde na comunidade, na atenção primária, realizamos visitas e construímos planos terapêuticos. (NASF B, E5)

Evidencia-se, portanto, a inserção de conteúdos relacionados à Saúde Coletiva e APS na graduação. Nesse sentido, foi observada no campo empírico a inserção de alunos em atividades de ensino e pesquisa. Não obstante, os profissionais formados nessa lógica atuavam com maior ênfase em atendimentos coletivos, apoio matricial e com melhor articulação com a ESF.

Por outro lado, o reconhecimento do despreparo para atuar no NASF, bem como a aparente intenção de maior qualificação profissional impulsionam à participação em processos formativos no nível de pós-graduação, conforme demonstrado na fala a seguir:
A faculdade direcionava somente para a reabilitação. Tudo que eu pude estudar em relação à promoção da saúde e prevenção na atenção primaria foi após a graduação, em cursos de especialização e cursos de aperfeiçoamento. (NASF A, E1)

As novas exigências do mundo do trabalho em saúde, consoantes à reorganização 
do modelo de atenção —o que requer a incorporação de novos saberes e práticasexige a adoção de estratégias de educação permanente para os profissionais de saúde, coerentes com as necessidades de formação, identificadas com base na realidade local, com vistas a qualificar a atenção à saúde.

Não obstante, defende-se o posicionamento de que é necessário ocorrer uma revisão crítica acerca dos processos educativos e formativos desenvolvidos pelas instituições de ensino superior, pois representa condição fundamental para que se desenvolva trabalho interdisciplinar, cogestão e produção do cuidado integral nos moldes propostos pelas diretrizes do NASF. Portanto, as respostas aos desafios atuais do trabalho em saúde requisitam a reflexão sobre a formação e acerca do perfil de competências pretendido para os profissionais da saúde, cujo enfoque não seja apenas no conhecimento técnico especializado, mas, sobretudo, nas habilidades e atitudes a serem desenvolvidas, com vistas a atender as necessidades de saúde da população, com a consciência da responsabilidade social envolvida na ação profissional (8).

É reconhecido, ainda, em conformidade com Bispo Junior (16), que a inserção de novos profissionais na saúde coletiva, particularmente nos NASF, tem como propósito ampliar o campo de prática das profissões e disponibilizar para a sociedade novos saberes capazes de contribuir para a promoção da saúde e qualidade de vida. Não deve se restringir, entretanto, os propósitos da ampliação do mercado de trabalho, mas ser esta pautada na responsabilidade social inerente a todas as profissões da área de saúde.

Com efeito, a qualificação dos processos de gestão e atenção à saúde requer a adoção de estratégias que permitam a reflexão crítica da prática e educação permanente com vistas à consolidação do modelo de atenção que se propõe materializar.

\section{As condições de trabalho do NASF: dificulda- des e facilidades}

A implantação dos NASF, no Município em estudo, de acordo com os entrevistados, ocorreu com dificuldades. As condições de trabalho constituem dimensão importante do processo de trabalho, influenciando a sua organização e qualidade. Nesse contexto, os profissionais revelam um cenário permeado por muitas dúvidas, incertezas e falta de orientação no pertinente ao trabalho a ser desenvolvido, de que as falas seguintes são representativas.

\footnotetext{
No início foi muito complicado, muito novo, não sabíamos o que fazer. Planejávamos as ações na segunda e na quarta tinha que mudar. (NASF A, E4)
}

No início foi muito difícil, nos faltaram orientação e apoio. (NASF B, E5)

Há de se reconhecer que, apesar da existência das diretrizes elaboradas pelo Ministério da Saúde para a atuação do NASF, os profissionais contratados revelaram dificuldades de operá-las no plano local, refletindo na dificuldade de organizar o trabalho. Por se tratar de estratégia inovadora, pois propõe ruptura com o modelo biomédico e inaugura outra lógica de produção do cuidado, a implantação do NASF implica a necessidade de a equipe criar espaços com dimensões de suporte para a realização das atividades de modo articulado com a ESF (8).

Ainda nesse âmbito, um grupo de profissionais revela que a infraestrutura das unidades de saúde não se mostra adequada à execução das suas atividades, denotando falta de condições de trabalho: 
[...] é difícil trabalharmos em postos onde não temos um ponto de apoio, uma sala, local para avaliarmos um paciente, um local para encaminharmos, dar um parecer. De pessoas é bem servido. Em uma unidade temos um ponto de apoio (sala), o que ainda é muito pouco. Embora se reconheça que geralmente os postos são construídos em casas antigas que se tornaram postos com dificuldade para ampliar, as vezes o terreno é pequeno, estreito, as salas que já existem. (NASF B, E4)

A estrutura das unidades é insuficiente não temos salas. Marcamos atendimento e quando chegamos temos que ir atrás de sala e não encontramos (NASF A, E5).

Segundo as falas, naquele momento de implantação, as equipes de NASF não dispunham de infraestrutura adequada à realização de suas atividades. Desse modo, a maioria das equipes inicia o trabalho em condições precárias de atendimento. Convém assinalar o fato de que, consoante aos relatos acima, foi possível constatar durante a observação do campo empírico a persistência do problema da falta de espaço destinado ao atendimento dos profissionais do NASF em algumas Unidades Básicas de Saúde da Família, as quais não dispunham de espaço adequado para o atendimento e atividades com grupos, considerando a inexistência, inclusive de sala de espera, sendo que os usuários aguardavam atendimento em corredores estreitos.

De modo divergente, outros trabalhadores asseveram que atuam em unidades nas quais a infraestrutura é adequada à execução de suas atividades, sejam individuais ou coletivas:

[...] na unidade de saúde $\mathrm{X}$ temos mais espaço. [...] temos uma sala de apoio. (NASF A, E1).
Evidenciou-se, por conseguinte, a existência de uma heterogeneidade no tocante à estrutura física e à capacidade instalada dos locais onde foram implantados os serviços de saúde no Município estudado, particularmente as equipes de NASF, resultante do planejamento da ampliação da rede de serviços. Constatouse que cada NASF está vinculado a 11 equipes da ESF, em territórios distintos. Assim, determinados serviços são implantados em estruturas em funcionamento, adaptadas a esta finalidade; outros resultam da criação e implantação de serviços, cujas estruturas são planejadas de acordo com o dimensionamento das equipes e dos serviços e ações de saúde ofertadas.

Confirma-se, consoante relatos dos entrevistados e observação dos processos de trabalho, a intensiva ênfase evidenciada nos atendimentos individuais. Tal situação contradiz o proposto nas diretrizes estabelecidas pelo Ministério da Saúde (3), ao estabelecerem que o trabalho dos NASF deve priorizar as ações coletivas, expressas principalmente no apoio matricial, na clínica ampliada e no atendimento compartilhado.

Não obstante, algumas razões podem justificar essa contradição, entre as quais foram referidas a ausência de formação dos trabalhadores que os qualificasse para o desenvolvimento do processo de trabalho, no momento de atuação das primeiras equipes de NASF no Município, além da aparente inadequação da infraestrutura dos serviços de saúde.

Em relação à infraestrutura, a observação das unidades de saúde permite inferir que a ambiência de algumas delas é inadequada, tanto no que se refere à estrutura física, quanto aos fluxos dos vários sujeitos. Tal aspecto compromete o atendimento aos usuários e, consequentemente, a humanização da atenção à saúde (5). Isso, contudo, por si só não deveria comprometer o atendimento 
a grupos, considerando que as ações de promoção da saúde poderiam ocorrer em outros espaços do território, por meio de articulação intersetorial, que possibilite parcerias com escolas, centros de convivências, igrejas, entre outros.

Outro obstáculo apontado pelos profissionais diz respeito à escassez de material e equipamentos necessários à realização das práticas de cuidado:

Quanto à estrutura, carece muito de material, de carro, de instrumentos de avaliação. (NASF B, E4)

Resultados semelhantes, em relação à falta de material, foram encontrados por Beleza (17), ao estudar o trabalho das equipes de Saúde da Família de Fortaleza. Nesse sentido, Guimarães (13), ao examinar a gestão no sus, particularmente no campo da saúde mental, considera que o funcionamento de serviços de saúde em condições precárias e, sobretudo, com falta de material para a execução das diversas ações de cuidado, reflete a desresponsabilização da Administração Pública no provimento de serviços essenciais ofertados à população. Isto, por sua vez, implica prejuízo da qualidade dos serviços e compromete a efetivação do direito à saúde.

As equipes de NASF, sob análise, funcionam segundo os parâmetros estabelecidos pelo Ministério da Saúde (3), particularmente, no referente ao número de equipes da ESF apoiadas. Os entrevistados, entretanto, apontam que a

Dificuldade maior é que não é um NASF para cada unidade, e o vínculo é diferente da ESF. Por serem muitas unidades, dificulta o trabalho. (NASF B, E7)

Não realizo atendimento individual, porque são cinco unidades de saúde não é possível dar continuidade ao atendimento. (NASF A, E1)
De acordo com os relatos, evidencia-se que, no período da pesquisa, o arranjo proposto pelo Ministério da Saúde, implantado no município em estudo, segundo o qual os NASF, modalidade I, se vinculam, no mínimo a oito equipes da ESF, na prática dificultou o trabalho das equipes (5). Assim, há sobrecarga de trabalho, bem como dificuldade na formação do vínculo entre algumas equipes, o que poderá comprometer a resolubilidade do cuidado.

A observação de campo tornou possível constatar que, quanto maior o número de equipes da ESF vinculadas ao NASF, maior a dificuldade de apoiar, bem como de se deslocar para cinco unidades de Saúde da Família, em territórios distintos. Assim, em algumas unidades de saúde, os profissionais conseguem desenvolver suas ações de modo articulado com a ESF. Noutras, o processo de trabalho expressa dificuldades de articulação, principalmente de avançar nas ações coletivas.

Sem desconsiderar os óbices indicados, os profissionais apontam alguns aspectos que favorecem e/ou facilitam o desenvolvimento de suas atividades:

Há um ano temos um coordenador do NASF por regional, o que facilitou muito. (NASF B, E1)

Destaca-se a ideia de que, no arranjo de gestão do Município sob análise, há descentralização dos processos gerenciais para as secretarias executivas regionais. Nesses termos foi instituída a coordenação regional do NASF, com papel de articular ações e equipes no território, bem como catalisar as demandas. Assim, parece ter sido possível resolver os problemas de organização do trabalho, repercutindo positivamente na atuação das equipes: 
A proposta de trabalho em equipe emerge como outra condição que favorece a execução do processo de trabalho do NASF.

Facilidade é nossa equipe, interesse da coordenação, interação e união da equipe. (NASF A, E1)

Equipe unida e querendo realizar o trabalho, os. ACS (NASF B, E1)

Nesse sentido, defende-se o argumento de que o trabalho em equipe, numa perspectiva interdisciplinar, tem o potencial de superar a fragmentação do cuidado. Para tanto, fazem-se necessárias a valorização da polifonia decorrente do efetivo exercício da multiprofissionalidade, bem como a diversidade de vozes e de discursos. Deve-se harmonizar as diferenças entre os saberes e práticas. A atuação dos diversos profissionais, portanto, deverá ser baseada na noção do agir em concerto, que se fundamenta no respeito às especificidades e responsabilidades de cada profissional (18).

Desse modo, o trabalho em equipe multiprofissional diz respeito à recomposição dos processos de trabalho que, mesmo se desenvolvendo de forma integrada, devem preservar as diferenças técnicas ou especificidades de cada trabalho e, ao mesmo tempo, articular as intervenções realizadas pelos componentes da equipe, na busca de concretizar a gestão compartilhada dos processos de cuidado.

A relação dos profissionais com os usuários foi considerada como facilitadora da atuação do NASF:

A facilidade é o acolhimento da população, desejo de buscar orientações. (NASF B, E5)

Entende-se que a ampliação da oferta de ações e serviços propicia expectativas positivas e induz a demanda dos usuários na busca por cuidado. Com efeito, faz-se necessário operacionalizar o acolhimento aos usuários como diretriz que possibilita novo modo de produzir cuidado, garantindo o acesso com responsabilização e resolubilidade (19). Nesses termos, torna-se premente reorganizar os processos de trabalho com vistas ao atendimento às necessidades de saúde, por meio da execução da clínica ampliada, mediante a escuta qualificada e a construção do vínculo.

Não obstante, se ressalta a ênfase na busca por orientações. Nesse âmbito, sinaliza-se a possibilidade de o NASF se afirmar como reestruturador no modelo de atenção à saúde, desenvolvendo ações capazes de responder às necessidades de saúde da população, sobretudo no âmbito da promoção da saúde e prevenção de doenças e agravos, tanto na dimensão individual quanto coletiva - reduzindo, portanto, os processos de medicalização (20).

\section{A articulação entre 0 NASF e a ESF: possibilida- des e limites na construção da integralidade do cuidado}

O NASF, ao configurar-se como equipe de apoio, particularmente, nos casos mais complexos, cuja abordagem extrapola a capacidade de intervenção do generalista, torna premente a necessidade de estabelecer articulações e parcerias com os profissionais que compõem a ESF, com vistas à construção da integralidade e ampliação da resolubilidade da APS.

Em relação ao estabelecimento de articulações entre as equipes NASF e ESF, evidenciaram-se distintas formas de relações, as quais recebem influência de determinantes diversos, conforme a fala a seguir:

Muitas vezes ficamos esperando a ESF porque somos apoio. Como não tem esse link iniciamos ações isoladas. Em algumas 
unidades articulação é bem tranquila e em outras não tem essa articulação. A demanda da ESF é muito grande e não inclui o NASF, temos que encontrar brechas, não tem um dia para sentar com o NASF, apenas na unidade $\mathrm{X}$ temos um dia específico para sentarmos com ESF. (NASF A, E1)

Tem equipe de PSF que atua em conjunto muito bem, mas até hoje tem equipes que não compreendem o nosso trabalho e não fazem articulação. São 11 equipes da ESF, onde somente em cinco a articulação ocorre de forma tranquila. (NASF B, E5)

A convergência das falas dos profissionais de ambas as equipes estudadas apontam (des) articulação das equipes de apoio e de referência, o que limita a operacionalização das diretrizes do NASF. Os determinantes desse processo estão expressos na aparente baixa compreensão da proposta de trabalho com a consequente resistência ao compartilhamento de agendas por parte das equipes da ESF e a grande demanda dos usuários, cujo contato direto é maior com a ESF, ficando o NASF somente para os casos complexos.

Outro aspecto que determina o modo como são estabelecidas as relações entre as equipes relaciona-se ao perfil dos profissionais, conforme demonstrado nas falas ora reproduzidas:

Tem unidade que o médico solicita e busca o retorno. Tem outras unidades que o médico nem conhece o NASF. Já as enfermeiras são boas de integração. (NASF B, E6)

Temos uma dificuldade para discutir casos devido a correria do médico. Não temos uma agenda para discutirmos casos. (NASF A, E5) de Saúde da Família X, a médica é excelente ela agrega, fortalece e tem compromisso.

No entanto, outros não têm compromisso. (NASF B, E3)

A convergência das falas sinaliza a heterogeneidade das articulações, sempre na dependência de atributos individuais dos profissionais, desvinculando-se de um compromisso maior com a proposta de atuação do NASF. Resultados semelhantes foram encontrados por Lancman et al. (2), quando revelam que diferenças na composição das equipes, formação e experiência profissional, bem como a organização e dinâmica do processo de trabalho, impactam na atuação destes profissionais, ocasionando o não compartilhamento de ações e induzindo o desenvolvimento de ações isoladas.

Foi possível evidenciar, no plano discursivo, o fato de que os profissionais atuantes no NASF, em suas práticas cotidianas, reproduzem ações que atualizam o modelo de atenção que se propõe superar. Nesse sentido, as falas revelam a dependência da equipe em relação ao profissional médico da ESF, reproduzindo a lógica do modelo médico-centrado (7), conferindo-se a este profissional a centralidade do seu saber/poder na organização do processo de trabalho em saúde. Por conseguinte, aspectos da humanização em saúde, que devem nortear a prática do NASF, como transversalidade dos saberes e práticas, gestão compartilhada do processo de trabalho, horizontalidade das relações, autonomia e valorização do trabalhador, não se concretizam no cotidiano das equipes.

Contrapondo-se a essa lógica, defende-se a posição de que a organização do processo de trabalho seja definida pela equipe multiprofissional, assumindo como eixo condutor das ações as necessidades de saúde do usuário. Busca-se romper com um modelo médicocentrado com vistas à consolidação de um modelo de atenção usuário-centrado, ou 
seja, organizado com suporte nos problemas de saúde da população, transformados em demandas de saúde (7).

A convergência das falas dos dois NASF estudados revela o entendimento comum de que a gestão, exercida pelos coordenadores de NASF e da ESF, possibilita maior integração entre as equipes. As falas em seguimento são representativas dessa afirmação:

\begin{abstract}
A integração também depende muito da coordenação PSF, pois surgem algumas ideias e buscam dar suporte ao nosso trabalho. (NASF B, E1)
\end{abstract}

Há um ano temos um coordenador do NASF [...], o que facilitou muito o trabalho. (NASF A, E2)

A organização e a gestão do processo de trabalho, consoante às diretrizes operacionais do NASF, deve ser pautada na corresponsabilização e cogestão. Envolvem o estabelecimento de pactuações entre gestor, equipe do NASF e da ESF, com definição criteriosa das estratégias a serem implementadas, considerando as dimensões relacionais e profissionais que permeiam o cotidiano de trabalho, com vistas à incorporação de novas concepções e valores coletivos (1).

Assim, os profissionais reconhecem que a atuação do coordenador potencializa a articulação e integração das equipes e ações de saúde no território, melhora a logística das unidades de saúde e agrega novos projetos na perspectiva de qualificar a atenção à saúde no território.

A construção da integralidade configura ponto transversal na discussão acerca da articulação entre as equipes e os processos gerenciais do cuidado no território. Sua efetivação, no entanto, parece não se concretizar em plenitude nos serviços estudados, conforme ilustra a fala seguir, representativa da maioria dos profissionais entrevistados:
A integralidade do cuidado acontece parcialmente, na medida no que não tenho acesso rápido aos pacientes que são demandados pelo PSF. Então, o atendimento se torna fragmentado. [...] Às vezes não se realiza atendimento domiciliar pela falta de carro. Temos também dificuldade de encaminhar os usuários para outros serviços. (NASF B, E4)

Percebe-se que as equipes trabalham em um cenário marcado pela escassez de suporte logístico necessário à consecução de suas atividades, a exemplo da dificuldade de transporte para visita domiciliária. Além disso, apresenta-se como limitação a precariedade da rede de atenção à saúde, considerando a inexistência, dificuldade de acesso e desarticulação em relação os distintos pontos de atenção, com vistas à continuidade do cuidado iniciado na APS. Situação semelhante é apontada no estudo realizado por Lancman et al. (2), onde também se indica que tal condição é anterior à implantação dos NASF.

A integralidade do cuidado envolve uma perspectiva terapêutica de técnicas e procedimentos, que abrange a escuta, o olhar, o toque e o respeito, que deve se estabelecer naquela relação intercessora entre trabalhador de saúde e usuário (21). De certo modo, passa de um ato inerente do trabalhador de saúde para uma necessidade de comprometimento com o usuário, de responsabilidade na relação no sentido de ajudar o usuário a crescer, de modo que ele consiga satisfazer suas necessidades de saúde, tornando-se responsável por sua vida. Implica, ainda, a possibilidade de estabelecer fluxos que permitam o acesso do usuário, na sua busca por cuidado, aos demais níveis de atenção.

\section{0 processo de trabalho: as ações voltadas para a organização dos serviços e a pro- 207 dução do cuidado}


No referente à organização do processo de trabalho e ao desenvolvimento de ações, a observação do campo empírico permitiu a identificação da ênfase na racionalidade instrumental e burocrática, concretizada na elaboração de instrumentos que permitam dar visibilidade à programação das atividades e à produtividade das equipes.

Assim, todos Os NASF elaboram um cronograma mensal e outro de atividades diárias, que representam a agenda de trabalho junto à população e às equipes da ESF apoiadas. Há, ainda, boletins que consolidam estas informações mensalmente, as quais são encaminhadas para a coordenação do NASF no Distrito de Saúde da Secretaria Executiva Regional.

Outros instrumentos são incorporados à gestão do processo de trabalho, com vistas à sistematização das ações desenvolvidas:

Hoje nos temos uns instrumentos de trabalho, a exemplo do PMA2 que facilitou muito. Neste temos o consolidado das nossas ações, que é repassado para as equipes PSF. (NASF A, E3)

Nós temos um formulário próprio para solicitar visitas e atendimento de grupo. A ESF mostra o problema e solicita o grupo. (NASF B, E2)

Nesses termos, as equipes dos NASF adotam estratégias que permitam o registro quantitativo de suas atividades e a constituição de fluxos de encaminhamentos. Há que se considerar, entretanto, a ideia de que o trabalho do NASF possui dimensão qualitativa, expressa no desenvolvendo de grupos e atendimentos compartilhados, o que questionável a potencialidade desses instrumentos no que se refere ao registro da produção ante a complexidade e especificidade deste trabalho. que o NASF A está vinculado a nove equipes e o NASF B atua junto a 11 equipes, desenvolvendo diversas atividades no território, delimitadas segundo a capacidade de intervenção das equipes e as demandas da ESF. Reitera-se que a observação permitiu perceber, contudo, que, quanto maior o número de equipes apoiadas e a extensão do território, maiores serão as dificuldades no referente ao desenvolvimento das ações de modo compartilhado e integrado.

Na busca pela pactuação do apoio, os profissionais dos NASF realizam reunião com distintos atores, na perspectiva de legitimar sua ação nos territórios, bem como estabelecer as parcerias necessárias para a execução das frentes de trabalho:

Existe reunião com as equipes com data certa (equipe marrom e vermelha), as outras eventualmente nos solicitam. (NASF A, E3)

Temos reunião mensal com o conselho o que facilita a visão do que é o NASF. (NASF B, E2)

Estas reuniões ocupam parte considerável da agenda de trabalho do NASF, revelam uma equipe de NASF organizada e preocupada em oferecer apoio à ESF. Ambas as equipes desenvolvem atendimentos, tanto individual quanto coletivo, segundo as necessidades de apoio das equipes da ESF:

[...] consultas, avaliação, atendimento individual, visitas domiciliares, matriciamento, sala de espera, grupos, poucos casos de atendimento compartilhado. (NASF A, E1)

Grupo de hipertenso, diabéticos e gestantes. [...] Atendimento individual e acompanhamento conforme a portaria. Realizo matriciamento em saúde mental, dou suporte de atendimento de pacientes que recebem alta do CAPS de modo mensal. PSE e as interconsultas. (NASF A E3) 
Realizamos salas de espera, visitas domiciliares, avaliação e encaminhamento, formação de grupos de idosos em parceria com outras instituições como CRAS, CAPS, Associação de hipertensos e diabéticos do Ceará, trabalhando em rede. Não fazemos atendimento individual, por conta do tempo, atendemos 11 equipes da ESF. Nós procuramos orientar e treinar cuidadores e na medida do possível prevenir doenças e encaminhar para um serviço que tenha essa disponibilidade de tempo. (NASF B, E4)

Evidencia-se heterogeneidade nas ações desenvolvidas pelos NASF, bem como diferenças e singularidades na atuação destas equipes; sobretudo, quando se identifica a noção de que as atividades são executadas segundo disponibilidade de tempo, infraestrutura das unidades e demandas das equipes da ESF.

Não obstante, os profissionais buscam desenvolver suas atividades em conformidade com as diretrizes que orientam o trabalho do NASF, no sentido de reorientar o modelo de atenção. A realidade local, todavia, parece impor obstáculos ao desenvolvimento de ações, particularmente no que se refere ao compartilhamento de atendimentos, que constitui dimensão técnico-operacional do apoio matricial, pois os profissionais revelam que o executam em menor quantidade quando comparado ao atendimento individual. Evidencia-se emergir como justificativa para tal a indisponibilidade de tempo dos profissionais da equipe de referência, conforme sinalizado anteriormente neste estudo. Constata-se, portanto, um hiato entre o trabalho prescrito e o executado na realidade local, em decorrência dos inúmeros desafios que se interpõem ao cotidiano dos serviços de saúde.

Desse modo, o trabalho do NASF, ao se configurar como apoio, suas ações são intrinsecamente relacionadas e dependentes dos modos de organização do trabalho das equipes da ESF. Por conseguinte, pode emergir necessidade de ajustes nas agendas e nos processos de trabalho de ambas as equipes - apoio e referência - em razão dos possíveis desencontros na organização dos processos de trabalho.

Assim, pode-se considerar que as equipes devem estar abertas ao aprendizado contínuo, com base na atenção à saúde e com o processo de trabalho coletivo, o que envolve flexibilidade e capacidade de interlocução dos atores envolvidos no processo.

\section{Considerações finais}

O estudo possibilitou uma aproximação com a organização do processo de trabalho dos NASF no Município onde o estudo foi realizado, permitindo a análise de aspectos diferentes que permeiam o cotidiano destes serviços de saúde, entre os quais se destacam a formação e a inserção dos trabalhadores na APS, as condições de trabalho, os modos como as equipes operam a gestão e a produção do cuidado em sua (des) articulação com a ESF.

A implantação dos NASF representa o esforço de operar políticas de saúde direcionadas à ampliação da oferta e aumento da resolubilidade da APS, por meio da inserção de profissionais de variadas formações em saúde, as quais devem atuar numa lógica de trabalho em equipe, cujo eixo condutor do processo de trabalho é a prática interdisciplinar, com foco na construção da integralidade do cuidado.

As diretrizes estabelecidas para Os NASF, entre elas a clínica ampliada, o apoio matricial e o projeto terapêutico singular, conferem-lhes características de uma proposta inovadora com potencialidades para a reorientação do modelo de atenção, reafirmando os princípios do sus. 
A análise da organização e gestão do processo de trabalho põe em relevo a existência de descompasso do trabalho prescrito —delineado com base nas diretrizes e normas que regulamentam a implantação e funcionamento das equipes - em relação ao trabalho efetivamente realizado. Diversos determinantes interferem nesse processo, os quais impõem adequações na execução das atividades dos NASF, com base no perfil técnico e relacional dos profissionais em sua articulação com a ESF, nas condições reais de trabalho nas unidades de saúde, nas necessidades de saúde do território e de apoio das equipes de referência. Assim, os modos como se organiza o trabalho no NASF podem ser diferentes a depender do contexto sanitário no qual está inserido.

Apresentam alguns desafios a serem superados com vistas à consolidação do novo modelo de atenção. Nesse sentido, a construção de trabalho compartilhado com ênfase nas ações coletivas, bem como a efetiva pactuação do trabalho e articulação entre NASF e ESF, persistem como propósitos a serem alcançados.

Reconhece-se o fato de que a efetiva mudança das práticas de saúde, direcionadas à qualificação da atenção, coerentes a diretrizes que norteiam a atuação dos NASF, voltadas a integralidade e humanização do cuidado, exigem reorientação nos modos de organizar os processos de trabalho, bem como abertura e disposição dos profissionais para empreender esforços com vistas a sua concretização.

A consolidação do NASF torna prementes, portanto, mudanças na formação dos profissionais na perspectiva de articular e aproximar o ensino e os serviços de saúde, a criação de condições de possibilidades para a execução do trabalho das equipes e a reorientação do modelo de gestão dos processos de trabalho, bem como a reinvenção das práticas em saúde, agora executadas com as ferramentas tecnológicas disponíveis, propostas para orientar a produção do cuidado por estas equipes.

Por fim, ressalta-se que o estudo apresenta limitações, entre elas o fato de que não foi possível se estabelecer comparações mais consistentes com outras experiências da mesma natureza, sobretudo por se tratar de uma proposta de trabalho relativamente recente, ainda com escassez de estudos sobre o processo de trabalho dessas equipes. Ademais, a pesquisa abrangeu somente duas equipes, as quais tem não apresentam o mesmo arranjo que referentes as categorias profissionais que as compõem.

\section{Referências bibliográficas}

1. Anjos KF, Meira SS, Ferraz CEO, Vilela ABA, Boery RNSO, Sena ELS. Perspectivas e desafios do núcleo de apoio à saúde da família quanto às práticas em saúde. Saúde em Debate. 2013 out/ dez; 37 (99): 672-80.

2. Lancman S, Gonçalves RMA, Cordone NG, Barros JO. Estudo do trabalho e do trabalhar no núcleo de apoio à saúde da família. Rev Saúde Pública. 2013 out; 47 (15): 968-75.

3. Brasil. Ministério da Saúde. Portaria GM 154 de 24 de janeiro de 2008. Cria os Núcleos de Apoio à Saúde da Família - NASF. Brasília, 2008 [Acesso em: 20 maio 2014]. Disponível em: <http://189.28.128.100/ dab/docs/legislacao/portaria154_24_01_08.pdf $>$.

4. Mattos RA. Repensando a organização da rede de serviços de saúde a partir do princípio da integralidade. In: Pinheiro R, Mattos RA, organizadores. Razões públicas para a integralidade em saúde: o cuidado como valor. Rio de Janeiro: Cepesc: Abrasco; 2007. p. 369-84.

5. Brasil. Ministério da Saúde. Política Nacional de Atenção Básica. Brasília: Ministério da Saúde; 2012.

6. Brasil. Ministério da Saúde. Diretrizes do NASF: Núcleo de Apoio à Saúde da Família. Brasília: Ministério da Saúde; 2010. (Caderno da Atenção Básica, n. 27).

7. Merhy EE. Saúde: a cartografia do trabalho vivo. 3. ed. São Paulo: Hucitec; 2007.

8. Nascimento DDG, Oliveira MAC. Reflexões sobre as competências profissionais para o processo de trabalho nos Núcleos de Apoio à Saúde da Família. O Mundo da Saúde. 2010; 34 (1): 92-96. 
9. Cunha GT, Campos GWS. Apoio Matricial e Atenção Primária em Saúde. Saúde soc. 2011 out/ dez. 20 (4): 961-70.

10. Minayo MCS. Hermenêutica-dialética como caminho do pensamento social. In: Minayo MCS, Deslandes SF, organizadoras. Caminhos do pensamento: epistemologia e método. Rio de Janeiro: Fiocruz; 2002. p. 83-108.

11. Minayo MCS. O desafio do conhecimento: pesquisa qualitativa em saúde. 13 ed. São Paulo: Hucitec; 2013.

12. Assis MMA, Jorge MSB. Métodos de análise em pesquisa qualitativa. In: Santana JSSS, Nascimento MAA, organizadores. Pesquisa: métodos e técnicas de conhecimento da realidade social. Feira de Santana: UEFs Editora; 2010. p.139-59.

13. Guimarães JMX. Inovação e gestão em serviços de saúde mental: incorporação de tecnologias e reinvenção no cotidiano dos Centros de Atenção Psicossocial [Tese]. Fortaleza: Programa de Doutorado em Saúde Coletiva, Universidade Estadual do Ceará; 2012.

14. Ceccim RB, Feuerwerker LCM. Mudança na graduação das profissões de saúde sob o eixo da integralidade. Cad. Saúde Pública. 2004 set/out; 20 (5): 1400-10.

15. Pereira IDF, Lages I. Diretrizes curriculares para a formação de profissionais de saúde: competências ou práxis? Trab Educ Saúde. 2013 mai/ago; 11(2): 319-38.

16. Bispo Júnior JP. Fisioterapia e saúde coletiva: desafios e novas responsabilidades profissionais. Ciênc Saúde Coletiva. 2010 jun; 15 (supl.1): 1627-36.

17. Beleza MS. O trabalho na estratégia saúde da família: estudo da satisfação dos profissionais [Monografia]. Centro de Ciências da Saúde: Fortaleza, Universidade Estadual do Ceará; 2012.

18. Bonaldi C, Gomes RS, Louzada APF, Pinheiro R. $\mathrm{O}$ trabalho em equipe como dispositivo de integralidade: experiências cotidianas em quatro localidades brasileiras. In: Pinheiro R, Barros MEB, Mattos RA, organizadores. Trabalho em equipe sob o eixo da integralidade: valores, saberes e práticas. Rio de Janeiro: IMS/UERJ: Cepesc: Abrasco; 2007. p. 53-74.

19. Brasil. Ministério da Saúde. Acolhimento nas práticas de saúde. Brasília: Ministério da Saúde; 2012.

20. Silva ATC, Aguiar ME, Winck K, Rodrigues KGW, Sato ME, Grisi SJFE, Brentani A, Rios IC. Núcleos de Apoio à Saúde da Família: desafios e potencialidades na visão dos profissionais da Atenção Primária do Município de São Paulo, Brasil. Cad. Saúde Pública. 2012 nov; 28 (11): 2076-84.

21. Pires VMMM, Rodrigues VP, Nascimento MAA. Sentidos da integralidade do cuidado na Saúde da Família. Rev enferm UeRJ. 2010 out/dez; 18(4): 622-27. 